\title{
O DISCURSO CITADO NA MACROESTRUTURA TEXTUAL DE ARTIGOS CIENTÍFICOS DE JOVENS PESQUISADORES
}

\author{
José Cezinaldo Rocha Bessa* \\ Universidade do Estado do Rio Grande do Norte \\ Pau dos Ferros, Rio Grande do Norte, BR
}

\section{Resumo}

Neste artigo, examinamos o discurso citado em artigos científicos de jovens pesquisadores, observando o uso desse mecanismo linguístico-discursivo em função da organização e distribuição das informações na macroestrutura textual. O trabalho se fundamenta em estudos do Círculo de Bakhtin e em trabalhos na perspectiva de Swales. Privilegiando uma abordagem qualitativa e uma análise de natureza interpretativa, a investigação contempla um exame de 10 artigos científicos de estudantes de mestrado das áreas de Letras e Linguística. A análise confirma que formas e finalidades de uso do discurso citato no artigo científico do jovem pesquisador sofrem inevitavelmente forte determinação da seção do artigo nas quais são mobilizadas, mas também do modo pessoal como o produtor seleciona e organiza as informações em seu texto, revelando a relação complexa e tensa entre estilo do gênero do discurso e estilo individual do produtor.

Palavras-chave: Discurso Citado; Artigo Científico; Jovem Pesquisador; Gênero do Discurso; Organização Retórica.

\section{SPEECH CITED IN THE TEXTUAL MACROSTRUCTURE OF SCIENTIFIC ARTICLES OF YOUNG RESEARCHERS}

\begin{abstract}
This article examines the speech quoted in scientific articles of young researchers, observing the use of this linguistic and discursive mechanism given the organization and distribution of information in the textual macrostructure. This work is based on studies of the Bakhtin Circle and works in the Swales perspective. Privileging a qualitative approach and an analysis of interpretative nature, the investigation includes a review of 10 scientific articles of master's students of the Language and Linguistics areas. The analysis confirms that forms and purposes of usage of quoted speech in scientific articles of young researchers inevitably suffer strong determination of the section of the article in which they are mobilized, but also if the personal way the producer selects and organizes information in his text, revealing a complex and tense relationship between the style of the speech genre and the individual style of the producer.
\end{abstract}

Keywords: Quoted Speech; Scientific Article; Young Researcher; Gender Discourse; Rhetoric Organization.

\footnotetext{
“ Possui graduação em Letras/Língua Portuguesa pela Universidade do Estado do Rio Grande do Norte e mestrado em Estudos da Linguagem, na área de concentração em Linguística Aplicada, pela Universidade Federal do Rio Grande do Norte. Doutorando em Linguística e Língua Portuguesa pela Universidade Estadual Paulista Júlio de Mesquita Filho. Atualmente é Professor da Universidade do Estado do Rio Grande do Norte. Concentra interesse pelos estudos na área de Letras, com ênfase em Linguística, em Linguística Aplicada e em Língua Portuguesa, dedicando-se especialmente a estudos informados pelas seguintes temáticas: gêneros do discurso, produção textual, ensino de língua materna, dialogismo, discurso citado, voz autoral, escrita e comunicação científica. Seu endereço de email é cezinaldobessauern@gmail.com
} 


\section{Introdução}

Neste artigo, examinamos o discurso citado em artigos científicos de jovens pesquisadores do campo das ciências humanas, 1 especificamente das áreas de Letras e Linguística, observando o uso desse mecanismo linguístico-discursivo em função da organização e distribuição das informações na macroestrutura textual. Nesse sentido, interessa-nos, neste texto em particular, responder às seguintes questões: como o jovem pesquisador cita na escrita do artigo científico? Que formas de citar ele mobiliza? Com que finalidades ele cita? Como se dá o funcionamento de formas e finalidades das citações em cada seção particular do gênero artigo científico?

Entendendo que cada seção de um artigo científico cumpre funções retóricas bastante específicas, já que cada uma delas se presta a uma finalidade particular e distinta no interior de um todo concreto e acabado, partimos da ideia de que o manejo das formas de citar o discurso do outro, nesses textos, resguarda especificidades do funcionamento de cada seção desse gênero. Logo, em gêneros do discurso como o artigo científico, composto de segmentos textuais com finalidades bem específicas, a seção do texto é um dos elementos centrais que condiciona aspectos como quantidade, formas e funções das formas de discurso citado. De uma perspectiva bakhtiniana, é o caso de dizermos que se reflete aí o estilo do gênero.

Porém, como inseparável do estilo do gênero está também o estilo individual do produtor (concebido como o autor criador do artigo científico/enunciador do ato de citar), é preciso considerar que a manifestação do componente da individualidade pode nos ajudar a melhor compreender, por exemplo, o fato de o produtor "optar" por citar ou não citar em determinado segmento textual do artigo, como na conclusão, ou por privilegiar citar com profusão ou não na seção de fundamentação teórica, assim como citar de forma literal ou reformulando o dizer, aspectos esses nem sempre observados em estudos sobre o fenômeno da citação em textos científicos escritos, e que tentaremos perseguir neste trabalho.

Nossa proposta de trabalho se inscreve no âmbito de estudos e reflexões que temos desenvolvido nos últimos anos em torno dessa temática. De modo mais específico e pontual, embora não exclusivamente, este texto apresenta reflexões e resultados de nossa pesquisa de doutoramento (BESSA, 2016), na qual investigamos manifestações do dialogismo no texto escrito produzido no âmbito universitário, centrando-nos mais especificamente no artigo científico produzido por jovens pesquisadores brasileiros (no caso, estudantes de mestrado2 acadêmico) das áreas de Letras e Linguística.

O presente estudo compreende, portanto, um capítulo essencial em nosso trabalho de compreensão do uso e funcionamento da citação em artigos científicos na medida em que sinaliza como o estudante de mestrado, na condição de sujeito-pesquisador em formação em pesquisa, vai se familiarizando com convenções próprias da esfera acadêmico-científica, particularmente em relação ao gerenciamento de vozes, à construção de uma voz autoral e ao domínio do gênero, e nela se engajando ativamente.

Dadas as preocupações didático-pedagógicas que nos movem como pesquisadores e profissionais que lidam diretamente com disciplinas com foco em ensino de textos (científicos, especialmente) na universidade, este trabalho visa, em última instância, explorar potencialidades e fragilidades de jovens pesquisadores na escrita de artigos científicos quanto ao gerenciamento de vozes, focalizando aqui especificamente o discurso citado.

No horizonte de nossos estudos e reflexões se encontra, pois, o objetivo de contribuir com o aprimoramento e a potencialização das práticas citacionais concebidas no âmbito mais geral das práticas escriturais de pesquisadores em processo de formação.

\section{Fundamentos teóricos}

As reflexões que fundamentam este trabalho estão ancoradas em duas perspectivas teóricas centrais: os estudos do Círculo de Bakhtin e estudos sobre organização retórica na perspectiva de Swales. De um lado, dos estudos do Círculo de Bakhtin, interessa-nos mais especificamente a discussão sobre gênero do discurso (mas não exclusivamente), para abordarmos a questão da relação entre o estilo do gênero e o estilo individual do produtor. De outro lado, na esteira dos estudos de Swales (1990) sobre a organização retórica do gênero, 
nosso foco é explorar a proposta de organização retórica do artigo acadêmico (artigo científico, na nossa acepção) seguindo Motta-Roth e Hendges (2010).

Considerando que uma compreensão mais profunda dos fundamentos das duas perspectivas teóricas nas quais nos amparamos exigiria de nossa parte uma discussão mais extensa que o espaço dessa publicação nos permite, tentaremos preservar, em linhas mais gerais e naquilo que é essencial, as ideias centrais que orientaram a análise que desenvolvemos em nosso trabalho.

\subsection{Considerações sobre gêneros do discurso na perspectiva do Círculo de Bakhtin}

Mesmo reconhecendo a amplitude do conceito de gêneros nas reflexões do Círculo e sua articulação com outros conceitos que compõem o pensamento bakhtiniano, propomo-nos a tratar da concepção de gêneros do discurso focalizando a relação entre estilo do gênero e estilo individual do produtor, o que não significa ignorar, evidentemente, sua articulação com outros conceitos tais como esfera da atividade humana, sujeito falante, cronotopo e autor/autoria.

Quando Bakhtin (2003, p. 266) afirma que "o estilo integra a unidade do gênero como seu elemento", quer nos parecer que aí ele delimita um ponto de orientação bastante instigante e fundamental sobre como devamos conceber o estilo. Ao fazer essa afirmação, o autor não está dizendo apenas que o estilo é mais um elemento do enunciado, como o é o conteúdo temático e a construção composicional, mas que não se pode concebêlo fora da relação indissociável com as formas típicas de enunciado. Essa posição acentua que cada forma típica de enunciado tem um estilo, o que implica entender que cada gênero tem um estilo particular, que o engendra, que o determina enquanto certa forma típica, não negando, porém, que cada sujeito falante, ao se expressar numa determinada forma de enunciado, imprime também a marca de sua individualidade, de sua "personalidade individual". Essa marca, em certos casos, pode ser expressa tão somente pelo tom, como pode se dar em um cumprimento a um vizinho como "Olá! Bom dia", conforme seja o estado emocional-volitivo do sujeito, em um determinado espaço-tempo.
Nesse sentido, é fundamentalmente importante retermos a afirmação bakhtiniana segundo a qual há gêneros do discurso mais propícios à manifestação de um estilo individual do falante. É o caso de termos em mente que, diferentemente do que ocorre na construção de um romance, em gêneros do discurso mais padronizados tais como memorando e regimento, as "brechas" para a manifestação de uma "personalidade individual" do falante existem; todavia, são mais restritas e/ou quase inexistentes.

Assim entendendo, queremos sustentar que, nas reflexões bakhtinianas, o grau de manifestação da "personalidade individual" do falante está, em certa medida, prevista/determinada pelo gênero, de modo que ela pode ser mais ou menos intensa, mais ou menos fortemente marcada, conforme o gênero do discurso seja mais ou menos padronizado, o que está diretamente ligado, portanto, às determinações da esfera de produção, circulação e recepção do gênero. Logo, é preciso enfatizar, por mais que isso possa parecer óbvio e redundante, que o olhar sobre o estilo supõe não perder de vista a esfera da comunicação discursiva em que os sujeitos falantes interagem e os gêneros que lhes são inerentes.

Como já apontado, na tensão com o estilo do gênero está o estilo individual do falante. Este aspecto não é menos importante na definição de estilo bakhtiniana, por razões que devamos observar de forma atenta. No que concerne ao aspecto da "personalidade individual" que se expressa no gênero é preciso enfatizar que esta não é única, nem algo fixo, estático, como se o sujeito falante tivesse um estilo definido de uma vez por todas e "aplicável" a todos os gêneros que ele produz, até porque, como diz Bakhtin (2003), nossa experiência discursiva individual está em contínua e permanente evolução, como reflexo do encontro com a palavra do outro.

Sustentamos essa última afirmação orientando-nos por, pelo menos, duas razões, que, a nosso ver, estão inteiramente relacionadas. De um lado, que é possível recuperar traços de um estilo individual que resiste no tempo e associados a um sujeito específico, mas ter em conta também que, em cada forma típica de enunciado e conforme seja o espaço-tempo, esse sujeito expressará traços estilísticos que só ocorrem naquela forma típica de enunciado. Afinal, como diz Bakhtin (2003, p. 266) 
“[...] em diferentes gêneros podem revelar-se diferentes camadas e aspectos de uma personalidade individual [...]", até porque a esfera comunicativa pode ser outra, $\mathrm{o}$ espaço-tempo é outro, o próprio sujeito falante é outro e os seus interlocutores também são outros. Por outro lado, que a marca do estilo individual pode ser mais ou menos intensa ou mais ou menos marcada, mais ou menos "livre e criadora", e, por conseguinte, provocadora de mais instabilidade no gênero, conforme o falante tenha um maior ou menor domínio sobre o gênero. Nesse sentido é que Bakhtin (2003) declara que a maioria dos gêneros do discurso se presta a uma reformulação livre e criadora, mas que é preciso dominá-los bem para empregá-los livremente.

Vemos, assim, que o estilo individual do falante tende a ficar mais em evidencia, ser mais marcado, quando se domina melhor o gênero (especialmente naqueles gêneros em que gozamos de mais liberdade expressiva), isso porque esse domínio maior do gênero - ao qual também está atrelada uma maior inserção do sujeito falante na esfera da atividade humana - o habilita a lidar com mais destreza e/ou maestria com as características próprias dos gêneros, e, por conseguinte, expressar-se de forma mais livre e criadora em determinado gênero.

\subsection{Apontamentos sobre a organização retórica do artigo científico}

Em nossa tese de doutoramento, a proposta de caracterizar a organização macroestrutural do artigo científico considera duas direções complementares: uma visão mais geral, que se pode denominar de base técnica, como estabelecida em boa parte dos manuais de metodologia científica e nas normas da ABNT NBR 6022:2002; e uma visão mais específica e direcionada, que se pode denominar de retórica, que está centrada nos estudos da linguagem e em particular em princípios teóricos da análise de gêneros discursivos acadêmicos e ensino de línguas para fins específicos proposta por Swales, como concebida por Motta-Roth e Hendges (2010).

Ainda que entendamos a necessidade de não ignorarmos a primeira direção tal como fizemos em nossa tese, dada sua influência e peso nas práticas comunica- tivas do universo acadêmico-científico, nesta exposição iremos nos concentrar apenas na segunda. Orienta-nos como pressuposto central a compreensão de que diferentes segmentos textuais do artigo científico desempenham diferentes funções comunicativas, determinando, por conseguinte, padrões de organização das informações para cada uma de suas seções.

É preciso, inicialmente, esclarecer que o trabalho de Motta-Roth e Hendges (2010) parte do modelo de análise estrutural de distribuição das informações que constituem os arranjos discursivos de gêneros textuais que ficou conhecido como modelo CARS (create-aresearch-space), desenvolvido por Swales (1990) para análise de introduções de artigos acadêmicos produzidos em inglês e amplamente utilizado para estudo de gêneros.

Fazemos a ressalva de que, diferentemente do que estamos acostumados a observar em artigos científicos de pesquisadores das áreas de Letras e Linguística, as autoras utilizam termos como Revisão de Literatura e Análise e discussão dos resultados, para se referirem às seções de Fundamentação Teórica e Análise dos dados ou Análise do corpus, respectivamente, pelas quais optamos em nosso trabalho. Esclarecidas essas questões, passemos à descrição das seções do artigo em conformidade com a perspectiva do trabalho de Motta-Roth e Hendges (2010).

$\mathrm{Na}$ definição das autoras, a introdução é a seção do artigo científico na qual o pesquisador contextualiza o problema de pesquisa dentro da área do conhecimento em que está inserido o trabalho, apresenta os objetivos e aponta a(s) justificativa(s) do estudo. O percurso do delineamento desses elementos na tessitura da introdução implica organizar as informações distribuindo-as em três movimentos retóricos: 1) apresentar um território de conhecimento; 2) construir um nicho para a pesquisa; 3 ) ocupar o nicho com seu trabalho.

Seguindo a proposta do modelo CARS de introdução de artigos desenvolvido por Swales (1990), as autoras apontam as estratégias 3 que compõem cada um dos três movimentos retóricos listados acima, que, esquematicamente, apresentamos no quadro a seguir: 


\begin{tabular}{|c|c|c|}
\hline $\begin{array}{l}\text { Apresentar um } \\
\text { território de } \\
\text { conhecimento }\end{array}$ & $\begin{array}{l}\text { Construir um } \\
\text { nicho para a } \\
\text { pesquisa }\end{array}$ & $\begin{array}{l}\text { Ocupar o nicho } \\
\text { com seu trabalho }\end{array}$ \\
\hline $\begin{array}{l}\text { 1. asseverar a } \\
\text { importância do } \\
\text { assunto; } \\
\text { 2. fazer gener- } \\
\text { alização (ões) } \\
\text { sobre ele; } \\
\text { 3. revisar itens } \\
\text { de pesquisa } \\
\text { prévia. }\end{array}$ & $\begin{array}{l}\text { 1. apresentar } \\
\text { argumentos con- } \\
\text { trários a estudos } \\
\text { prévios; } \\
\text { 2. identificar } \\
\text { lacunas no } \\
\text { conhecimento } \\
\text { estabelecido; } \\
\text { 3. fazer ques- } \\
\text { tionamentos } \\
\text { sobre o assunto; } \\
\text { 4. continuar } \\
\text { uma tradição } \\
\text { de pesquisa já } \\
\text { estabelecida. }\end{array}$ & $\begin{array}{l}\text { 1. definir os obje- } \\
\text { tivos ou as princi- } \\
\text { pais características } \\
\text { do trabalho; } \\
\text { 2. anunciar os } \\
\text { principais resulta- } \\
\text { dos; } \\
\text { 3. indicar a estru- } \\
\text { tura do artigo }\end{array}$ \\
\hline
\end{tabular}

Quadro 1: Critérios de organização retórica de introdução de artigos com base em Motta-Roth e Hendges (2010)

A revisão da literatura pode, segundo as autoras, constituir uma seção específica ou aparecer dentro da seção de introdução. Como seção específica, ela se localiza depois da introdução e antes da metodologia. Se pensarmos a organização macroestrutural de artigos das áreas de Letras/Linguística, essa ordem também não deve ser vista como uma "camisa de força", por razões que já explicitamos mais acima.

A revisão da literatura é a seção do artigo em que o pesquisador visa situar o seu trabalho dentro do conjunto de produções de sua área do conhecimento, recortando aqueles estudos que são mais diretamente relevantes para o desenvolvimento de sua pesquisa. $\mathrm{O}$ aproveitamento da revisão da literatura se expressa, na construção do artigo, de diferentes formas, "destacando conceitos, procedimentos, resultados, discussões e conclusões relevantes para o trabalho" (MOTTA-ROTH e HENDGES, 2010, p. 91). O foco é, ainda de acordo com as autoras, discutir as questões que dão conta do estado da arte da área em que a pesquisa está inserida. Por isso, nessa seção é dada importância central à referência a outras vozes, autores, pesquisas, fontes. $\mathrm{Na}$ construção e organização das informações nessa seção é fundamental que o pesquisador, como um "regente de um coro de vozes" no qual se constitui, indique claramente o pertencimento das ideias reportadas e procure fazer os autores citados dialogarem entre si.
A seção de metodologia objetiva apresentar os procedimentos metodológicos de um estudo/pesquisa. Se pensarmos de uma perspectiva das ciências da saúde, exatas ou naturais, poderíamos, sendo mais precisos, dizer de outro modo: a seção de metodologia visa apresentar os materiais e métodos adotados em um estudo/pesquisa. Day (2001, p. 36) confirma essa definição ao afirmar que "a principal finalidade da seção de Materiais e Métodos é descrever (e, se for necessário, defender) o delineamento experimental e então fornecer detalhes suficientes, de forma que um pesquisador competente possa repetir o experimento." Isso inclui descrever cuidadosamente e com riqueza de detalhes os participantes, sujeitos, instrumentos, procedimentos, critérios, variáveis/categorias de análise etc., dada a importância que se confere à reprodutibilidade da pesquisa no fazer científico dessas áreas.

No vasto campo das humanidades, em que as estratégias de investigação tendem a divergir daquelas das áreas referidas no parágrafo anterior, pode-se dizer que, via de regra, o pesquisador descreve as ações, métodos, técnicas e os procedimentos de coleta, registro, organização e análise dos dados/corpus implicadas na realização da pesquisa.

Como verificado em pesquisas citadas por MottaRoth e Hendges (2010), cada área do conhecimento e disciplinas específicas constroem modos bastante específicos de organizar a seção de metodologia, de tal maneira que é difícil afirmar se as descrições da seção de metodologia apresentadas em tais pesquisas podem ser aplicadas para outras áreas. Talvez, em disciplinas, como é o caso de medicina e bioquímica, com estratégias de investigação semelhantes ou parecidas, possa haver alguma compatibilidade na organização dessa seção, como indica estudo de Kanoksilapatham (2005), citado pelas autoras. Porém, em disciplinas com estratégias de investigação diferentes, a impossibilidade de generalizar um modelo de organização de metodologia parece ser bastante evidente.

Não parece razoável, portanto, reportarmo-nos a nenhum dos modelos de organização retórica da metodologia que as autoras apresentam, já que eles se voltam para outras disciplinas, a saber, medicina, bio- 
química e administração, sendo, certamente, de pouco proveito para as áreas de Letras e Linguística.

Em artigos produzidos por pesquisadores de disciplinas da área de ciências humanas, a seção de análise e discussão dos resultados é a parte do artigo na qual o pesquisador apresenta os dados de seu estudo/pesquisa, descreve-os e os interpreta. A configuração dessa seção pode variar bastante em outras áreas, podendo dela fazer parte inclusive as principais conclusões do estudo, como ocorre em determinados artigos da área da medicina, como anotam Motta-Roth e Hendges (2010) e Day (2001). Nas produções das áreas de Letras/Linguística, é mais comum ocorrer uma ou mais subseções, geralmente reunidas sob o rótulo de análise dos dados ou análise do corpus, nas quais o pesquisador descreve e/ou interpreta os dados, fundamentando-se na teoria elaborada, não se preocupando em apresentar nela ainda as conclusões de sua pesquisa.

Nas áreas do núcleo da saúde e de exatas, por exemplo, há ainda uma tendência para separar, em duas seções distintas, resultados e discussão, como comprovam descrições apresentadas por Volpato (2010) e Day (2001). Na parte de resultados o foco é precisamente a descrição dos resultados encontrados, e, na parte de discussão, o eixo norteador é apresentar uma discussão dos dados fundamentada em estudos prévios, explicitando relações entre os fatos observados, realizando comparações dos achados com constatações de outras pesquisas e construindo significados para os resultados.

Considerando que, sobretudo no domínio das ciências humanas, a conclusão aparece como uma seção independente da discussão, tal seção apresenta finalidades, características e formas de organizar as informações específicas desse domínio. Podemos dizer, muito genericamente, que a principal finalidade da seção de conclusão é sumarizar os principais resultados e apresentar as conclusões a que o pesquisador chegou com a pesquisa realizada.

Levando em conta os apontamentos acima, cabenos acrescentar, por fim, que, como prática comunicativa da esfera acadêmico-científica, o artigo científico se inscreve na dinâmica da produção do conhecimento da área disciplinar em que está inserido o pesquisador. É a cultura disciplinar que define as "regras do jogo", o tipo de artigo, seus usos, bem como sua organização macroestrutural, que, embora seguindo convenções próprias da esfera-acadêmico-científica, se ajusta às especificidades das condições concretas de sua produção, recepção e circulação (o que implica considerar se o artigo é publicado, por exemplo, numa revista $\mathrm{X}$ ou $\mathrm{Y}$ ) e ao estilo particular e individual de escrita do pesquisador.

\section{Metodologia}

Caracterizamos este trabalho como de natureza interpretativa, assumindo que o movimento interpretativo realizado pelo pesquisador compreende um percurso investigativo que inclui a descrição, a análise e a interpretação como procedimentos inter-relacionados que colaboram para assegurar uma compreensão em profundidade do objeto de estudo. Nesse sentido, privilegiamos também o enfoque qualitativo, tendo em conta que nosso propósito é olhar para o objeto de estudo tentando ver nele os seus aspectos singulares, particulares, sem, evidentemente, ignorar regularidades, e sem pretensão, portanto, de construir generalizações.

A análise empreendida contempla um exame de 10 artigos científicos produzidos por estudantes de mestrado acadêmico (concluído ou em andamento) das áreas de Letras e Linguística selecionados dos anais da VII edição do Congresso Internacional da ABRALIN, realizada em 2011, na Universidade Federal do Paraná. A escolha dos anais dessa edição levou em conta, dentre outros critérios, o fato de ser o congresso mais recente da referida associação cujos anais estavam disponíveis, nos formatos de CD-room e on-line, no período de nossa coleta.

Dentre os vários artigos científicos publicados nos referidos anais, estabelecemos como critério selecionar aqueles que, em alguma medida, assumissem textualmente adotar concepções teóricas dos estudos bakhtinianos ou teoria/análise dialógica do discurso. Como certos pressupostos da perspectiva teórica dos estudos bakhtinianos constituem um lugar para o qual convergem estudos desenvolvidos em diferentes domínios disciplinares da linguística, teórica e aplicada, praticada no Brasil, especialmente nesses últimos 20 anos, e como esses pressupostos têm sido incorporados em documentos oficiais do ensino, com declarada 
relevância nesses dois casos, pareceu-nos oportuno e produtivo considerar (dados os objetivos de nossa pesquisa de doutoramento, da qual este texto constitui um recorte) sua recepção pelo jovem pesquisador, sobretudo quando se considera ainda afirmações como essa apresentada por Rodrigues (2004, p. 415): "no Brasil e em outros países, as concepções teóricas de Bakhtin têm sido retomadas e citadas por muitas dessas pesquisas, mas, muitas vezes, com efeitos de interpretação e apropriação diversos." (grifos nossos).

Nesse sentido, estabelecemos que seriam considerados não apenas aqueles artigos científicos que se inscrevessem propriamente no que se convencionou denominar, aqui no Brasil, de Análise Dialógica do Discurso ou estudos bakhtinianos, mas também artigos inscritos em domínios como Linguística do Texto, Linguística Aplicada, Análise do Discurso de Orientação Francesa, por exemplo, já que nesses domínios, como sabemos, se produzem, e com bastante vigor e entusiasmo, trabalhos que se apropriam das concepções teóricas dos estudos bakhtinianos e/ou que com elas dialogam. Os 10 artigos selecionados foram aqueles, portanto, que satisfizeram a essa condição. Neles, os estudos bakhtinianos comparecem, ora como a orientação teórica principal ou como a única tomada como fundamento, ora como uma orientação mais acessória ou periférica, no sentido de fornecer tão somente uma visão mais geral sobre o objeto de estudo, sobretudo naqueles casos em que o produtor recorre basicamente à concepção de linguagem ou de gênero do discurso, para desenvolver estudos que tomam pressupostos da Linguística do Texto, da Linguística Aplicada ou da Análise do Discurso de orientação francesa etc., como ancoragem teórica principal.

Assumimos, em nossa análise, a proposta de organização macroestrutural do artigo científico composta das seguintes seções: introdução, fundamentação teórica, metodologia, análise dos dados e conclusão, por entendermos que essa configuração reflete mais fielmente o modo como se organizam macroestruturalmente os artigos da área, e, em particular, aqueles que compõem o corpus de nossa pesquisa. Dados os propósitos de nosso trabalho, não consideramos, para fins de análise, o resumo (em língua portuguesa) que consta antes da seção de introdução de cada artigo. Mesmo cientes de que o resumo (ou abstract, em outros casos) seja um elemento constitutivo do artigo científico, nossa análise não contempla esse elemento, porque compreendemos que $o$ aspecto da referência a autores que nele se manifesta parece-nos pouco produtivo quando temos em conta os objetivos de nosso trabalho.

Com tais direcionamentos em mente, partimos para a leitura e exame dos 10 textos do corpus, realizando um movimento que seguiu do corpus à teoria e desta retornando àquele. Esse procedimento abriu perspectivas para, por um lado, tomarmos certas categorias que recobrem a abordagem do fenômeno do discurso citado/relatado/formas de representação do discurso outro/formas de referência ao discurso do outro presentes nos estudos bakhtinianos, de Authier-Revuz (1998, 2004, 2008), de Maingueneau (1996, 1997, 2008, 2011), de Boch e Grossman (2002), de Boch (2013), entre outros, como ponto de partida de nossa análise; e, por outro lado, explorarmos outros aspectos dos diálogos que caracterizam o dizer do jovem pesquisador que o contato (leitura e análise) com o corpus foi relevando à medida que íamos nos familiarizando mais com este.

Explicitados esses direcionamentos, tratamos, agora, de apontar o percurso analítico-interpretativo de que resultou o trabalho de pesquisa. Tal percurso compreendeu, pois, os seguintes procedimentos:

1. Após uma leitura exploratória inicial para conhecer cada um dos textos do corpus no que concerne ao conteúdo e organização textual, procedemos à realização de leitura e releitura do material, com vistas a identificar e destacar enunciados que, no texto do jovem pesquisador, pudessem ser interpretados como manifestações da presença da palavra alheia;

2. Sistematização e agrupamento dessas manifestações em categorias analíticas;

3. Descrição de categorias de análise correspondentes a essas manifestações;

4. Seleção de fragmentos/excertos dos textos do corpus para ilustrar as categorias de análise elaboradas; 
5. Realização de análise qualitativa do corpus, focalizando a descrição e interpretação das manifestações da presença da palavra alheia identificadas nos textos.

Por fim, é necessário dizermos que, no decorrer da análise do corpus, as categorias elaboradas são exemplificadas por excertos que são considerados representativos, sobretudo do ponto de vista daquilo que é da ordem do singular, mas também daquilo que aponta para regularidades, no que se refere às manifestações de relações dialógicas que constituem o dizer do jovem pesquisador.

\section{Uso e funcionamento do discurso citado na macroestrutura textual do artigo científico}

Uma primeira constatação sobre o funcionamento das formas de discurso citado nos artigos científicos analisados é que seu uso se concentra de forma mais acentuada na seção de fundamentação teórica. Esse uso mais acentuado se deve, certamente, não ao fato de a fundamentação teórica ser a seção que, na maioria dos artigos analisados, apresentou maior volume textual (ou seja, por ser a mais extensa) e nem tanto ao fato de seus produtores se encontrarem na condição de jovens pesquisadores, mas fundamentalmente por ser uma característica própria do gênero o estabelecimento, na referida seção, de um diálogo mais intenso e recorrente com o conjunto de trabalhos da área de conhecimento em que o pesquisador está inserido, seja para apresentar e discutir conceitos, seja para problematizar abordagens teórico-metodológicas, seja para traçar e melhor definir categorias de análise, etc. Logo, nessa seção, fazer referência ao dizer de outros estudos/autores se constitui uma estratégia essencial para que o pesquisador situe sua reflexão na argumentação científica (BOCH, 2013).

Dentre os vários aspectos que poderíamos explorar em relação ao discurso citado na seção de fundamentação teórica, escolhemos enfatizar particularmente este: como o produtor constrói o seu dizer em um permanente entrelaçamento entre paráfrase e reprodução literal de palavras, procedimento esse que, não raras vezes, é entendido como uma forma de "apagamento" da voz do produtor. Observemos, pois, o excerto a seguir, para podermos explorar o aspecto referido.

(01)

O autor afirma em Estética da Criação Verbal que são infinitas a riqueza e a variedade dos gêneros do discurso, destacando sua heterogeneidade. À medida que a sociedade vai evoluindo e se tornando mais complexa, o gênero vai se adaptando a ela. Para Bakhtin (1992, p. 280), "ficaríamos tentados a pensar que a diversidade dos gêneros do discurso é tamanha que não há e não poderia haver um terreno comum para seu estudo." (AC07, p. 987)4

$\mathrm{O}$ excerto acima mostra que o seu produtor se propõe a discutir o conceito de gêneros do discurso na abordagem bakhtiniana. É possível observarmos, pelo destaque do sublinhado, como o produtor faz uso reiterado das palavras de Bakhtin, ora tentando parafraseia-las, ora reproduzindo-as literalmente, o que denota que, nos segmentos textuais desse artigo, o dizer do produtor se constitui nesse jogo entre reproduzir literalmente e tentar se expressar com as próprias palavras.

Uma leitura mais exigente diria que o produtor se apaga, que ele se auto silencia. Uma leitura menos exigente - não necessariamente mais acertada e da qual compartilhamos - sugere pensar que o produtor fala/enuncia com e por meio da palavra do outro, que o constitui. E, nesse sentido, sugere pensar ainda que tal procedimento pode ser resultante de uma dificuldade de o produtor se autorizar a dizer com as próprias palavras, quanto um reflexo da complexidade da temática e da relação de pouca proximidade do produtor com a abordagem de gêneros evocada, como pode ser, em última instância, um reflexo do estágio de formação do produtor como pesquisador. Esse jogo entre citar reproduzindo literalmente e parafrasear, na seção de fundamentação teórica, parece ser constitutivo do dizer de um sujeito que, num estágio inicial de formação como pesquisador, se vê sob a exigência, a um só tempo, de se familiarizar com as convenções da esfera acadêmica e do discurso disciplinar e de situar sua reflexão na argumentação científica.

Se os jovens pesquisadores citaram bastante e por meio de formas as mais variadas (de evocação a dis- 
curso direto) na seção de fundamentação teórica, nas demais seções (introdução, metodologia, análise dos dados e conclusão), eles tendem a citar bem menos e a restringirem o repertório de formas de discurso citado. É possível verificar que, nessas seções, ocorre um manejo muito particular dessas formas por cada pesquisador, uns citando mais, outros citando um pouco menos, uns utilizando mais determinada forma de citar, outros usando bem menos tal forma, de modo que aí a tensão entre as restrições do gênero e o estilo individual do pesquisador se põe em evidência mais nitidamente.

É preciso considerar ainda que, em alguns casos, esse uso pouco expressivo do discurso citado, particularmente em seções como introdução, pode ser um indicador tanto do pouco domínio das convenções que recobrem o gênero e as formas de citar por parte do jovem pesquisador, como das formas de produzir conhecimento da área disciplinar em que se inscrevem os pesquisadores. No caso da seção de introdução, foi possível observar que, na maioria dos artigos analisados, parece não haver por parte do jovem pesquisador uma preocupação em recuperar e citar pesquisas prévias na temática do trabalho, como previsto no modelo CARS proposto por Swales (1990). A única exceção feita fica por conta de $\mathrm{AC} 08$, em passagens como a transcrita abaixo, na qual o produtor retoma, por meio de evocações, trabalhos de outros pesquisadores dentro de seu propósito de problematizar e melhor delimitar seu objeto de pesquisa:

(02)

Contudo, a ampliação da produção escrita científica de alunos nem sempre vem acompanhada da qualidade, como tem indicado relatórios de avaliação do PIBIC e pesquisas desenvolvidas (MOTTA-ROTH, 2003; RAMIRES, 2007; BOCH, GROSSMANN, 2001, 2002; PEREIRA, 2007; entre outros). (AC08, p. 2068)

Esse caso em particular aponta, ao menos parcialmente, na direção do que afirma Swales (1990) sobre o uso das citações na seção de introdução de artigos científicos. O autor observa que se costuma citar trabalhos prévios para se mostrar que existe um problema de pesquisa e o que já se sabe acerca do assunto/ temática, com vistas a estabelecer os limites das pesquisas antecedentes e criar um espaço de pesquisa para o trabalho que se pretende realizar. Long (2004) reafirma essa ideia de Swales (1990), quando coloca o aspecto da relação de um trabalho de pesquisa com os resultados de outras pesquisas como um dos elementos essenciais da construção e da formulação por escrito de uma problemática de pesquisa. Porém, na maioria dos artigos examinados, os jovens pesquisadores citam, na introdução, orientados geralmente por outras finalidades. AC04, AC05, AC08 e AC09, por exemplo, citam para delimitar categorias/conceitos e a perspectiva teórica que fundamenta o trabalho. Como demonstração, tomemos o excerto de AC04, em cuja passagem o produtor explicita a perspectiva teórica - bakhtiniana - e conceitos - gênero discursivo e transmutação - de tal perspectiva:

(03)

A abordagem teórica de Bakhtin 2003), no que se refere ao conceito de gênero discursivo, transmutação e análise feita das marcas de transmutação, permitiu que o artigo atribuísse ao scrap o status de gênero emergente da mídia digital. (AC04, p. 4306)

Há aqueles, como AC01, AC02, AC03, AC05, AC09 e AC10, que citam para explicitar filiação a um posicionamento teórico assumido por um (ou por mais de um) determinado autor e do qual compartilham em seus trabalhos, como exemplifica o excerto a seguir, no qual o produtor de AC03 revela compartilhar de um certo modo de conceber a linguagem, que é aquele que não dissocia as práticas de linguagem das práticas sociais:

\section{(04)}

O mesmo Bakhtin (1997) atribui uma característica social aos gêneros. Portanto, analisar gêneros numa perspectiva sociorretórica - à qual nos filiamos -, que é herdeira dos pensamentos bakhtinianos, é afirmar que as práticas de linguagem nada mais são do que reflexos de práticas sociais. E misturas de diferentes naturezas são próprias do ser humano. Antes de os gêneros se mesclarem, há toda uma prática social que também se mistura, que busca fugir dos cânones pelos mais variados motivos, o que leva, muitas vezes, a mixagem de elementos de diferentes culturas, resultando em 
uma só estrutura, um só objeto. Isso, então, acaba se espelhando na língua. (AC03, p. 4350)

Como se pode ver, as citações na seção de introdução estão mais diretamente associadas ao esforço dos jovens pesquisadores de explicitarem a perspectiva teórica e/ou autores que adotam e de retomarem conceitos e posicionamentos teóricos que fundamentarão a pesquisa. Nossa hipótese é que tais formas de dialogar com o discurso do outro, que não deixam de assinalar o componente da individualidade do estilo do produtor, reflitam, antes de tudo, um direcionamento dos modos de construção de artigos científicos de pesquisadores mais experientes da área disciplinar, nos quais os jovens pesquisadores acabam, de um modo ou de outro, com maior ou menor intensidade, se espelhando.

Não se pode descartar também, destacamos novamente, a hipótese de desconhecimento por parte dos jovens pesquisadores das convenções que apontam que, na introdução de um artigo científico, o pesquisador pode, por exemplo, citar trabalhos prévios de outros autores no delineamento da problemática de seu trabalho. Uma outra hipótese ainda é que, em alguns casos, a configuração da introdução do artigo científico pode ser um reflexo do trabalho de "recortar" o texto da dissertação (ou de um relatório de pesquisa elaborado previamente) e adequá-lo ao "formato" do artigo prescrito pela organização do evento. É possível acreditar que esse movimento de recortar não seja um trabalho tranquilo, sem algum grau maior ou menor de dificuldade, dadas as limitações que, não raro, se apresentam, quando o texto original tem 20 ou 30 páginas e o produtor precisa transformá-las em 08 ou 10, para atender às normas de um evento e/ou periódico.

Quanto ao uso do discurso citado na metodologia, é preciso partirmos do fato de que nem sempre os artigos científicos examinados apresentam essa seção, o que aponta para uma especificidade do campo disciplinar, já que em determinadas disciplinas, sobretudo no domínio das ciências da saúde, a estrutura IMRAD (Introduction, Methods, Results, and Discussion - Introdução, Métodos, Resultados e Discussão) se impõe, de modo que o pesquisador, necessariamente, precisa esboçar uma seção metodológica na composição de seu artigo.
No corpus da pesquisa, somente 03 dos produtores (AC03, AC04 e AC06) esboçaram uma seção dedicada especificamente a apresentar a metodologia do trabalho, ainda que outros produtores como AC01, AC07 e AC10 tenham feito, geralmente na seção de introdução, alguma descrição metodológica da pesquisa realizada. Este é o caso de AC10 que, em dois momentos da seção de introdução de seu texto, explicita o direcionamento metodológico que assume em seu trabalho. No primeiro momento, AC10 explicita como classifica o tipo de pesquisa que desenvolve, sem fazer menção a qualquer autor (embora vozes se manifestem na definição de abordagem sócio-histórica e de pesquisa qualitativa), e, num segundo momento, relaciona o tipo de pesquisa (pesquisa documental) a determinados autores, sem, porém, explicitar como tais autores concebem a pesquisa documental, o que parece pressupor que não haja divergência no modo como esses autores concebem esse tipo de pesquisa ou, talvez, que o produtor suponha um conhecimento partilhado com seus interlocutores:

(05)

Este estudo insere-se no campo da Linguística Aplicada, configura-se como sendo de natureza qualitativa e de abordagem sócio-histórica, uma vez que esta concebe a construção do conhecimento como uma construção que se realiza entre sujeitos. Esta pesquisa tem um caráter descritivo e exploratório e pretende utilizar-se dessa abordagem qualitativa para análise dos resultados apresentados. Sabemos que a pesquisa qualitativa costuma ser direcionada e não busca enumerar ou medir eventos e, geralmente, não emprega instrumental estatístico para análise dos dados; seu foco de interesse é amplo e dela faz parte à obtenção de dados descritivos mediante contato direto e interativo do pesquisador com a situação objeto de estudo, por isso ela nos permite um aprofundamento no mundo dos significados das relações humanas. (AC10, p. 3034).

(06)

Fundamenta nesses aspectos, é que optamos por desenvolver uma pesquisa documental (MOREIRA e CALEFFE, 2008) e (FREITAS, 2003), embasada nos documentos elaborados pelo MEC para o programa: Guia Geral que se divide em cinco Unidades [...] (AC10, p. 3035). 
Dentre os 03 produtores que esboçaram uma seção de metodologia, apenas AC06 apresentou uma descrição metodológica um pouco mais detalhada, ultrapassando mais de 02 parágrafos, que foi a extensão com mais regularidade nessa seção dos artigos analisados, conforme pudemos constatar em AC01, AC03, AC04 e AC08.

Numa exposição metodológica de extensão de pouco mais de 01 página e distribuída em subseções intituladas objeto de pesquisa, constituição do corpus e procedimentos de geração de dados, AC06 fez uso de apenas uma forma de discurso citado, tendo como propósito explicitar a orientação teórica que fundamentara a análise do corpus de sua pesquisa.

\section{(07)}

\subsection{CONSTITUIÇÃO DO CORPUS}

O corpus vai se constituindo à medida que avançamos na nossa análise e os procedimentos utilizados, fazem parte também da constituição do corpus. A nossa orientação teórica a qual vê a linguagem como prática social, norteada pelos pressupostos de Bakhtin, é base para a nossa analise. (AC06, p. 965)

Isso indica que a quase total inexistência de referência ao discurso do outro na seção de metodologia pode estar associada ao fato de que não há, na maioria dos artigos analisados, uma preocupação voltada para uma descrição metodológica mais detalhada e precisa, mas também ao fato de não se verificar, com raras exceções, uma preocupação dos produtores de justificar, com base em autores, escolhas metodológicas da pesquisa, seja quanto à filiação teórica que assumem, seja quanto ao tipo de pesquisa que realizam ou ainda quanto aos procedimentos que adotam. Tal constatação pode indicar, em última instância, que, dadas as especificidades dos modos de fazer pesquisa próprios da área disciplinar na qual se situa o trabalho do pesquisador, ou, talvez ainda, dada a especificidade do gênero do discurso no que concerne a suas condições de produção e circulação, questões relativas à metodologia do trabalho de pesquisa sejam vistas como pouco pertinentes e/ou relegadas a um segundo plano na constituição do texto.

$\mathrm{Na}$ seção de análise dos dados, o uso do discurso citado parece sugerir mais diretamente a manifestação de traços da individualidade dos jovens pesquisa- dores, considerando que se nota claramente que alguns produtores (AC03, AC07 e AC08) citaram com mais profusão, enquanto outros (AC04 e AC09) citaram menos e outros ainda (AC02 e AC06) quase não citaram.

O que se pode observar aí é que o uso do discurso citado nessa seção parece se moldar particularmente à maneira como cada pesquisador sistematiza sua análise e como relaciona dialogicamente seu dizer com o dizer dos autores nos quais se fundamentam, em outros termos, que atitude responsiva ele assume em relação aos autores que cita: se de respaldo, se de questionamento, se de discordância, entre outras. Ilustremos retomando os casos de AC02, AC03 e A08.

$\mathrm{O}$ produtor do AC02 sistematiza sua análise com foco na demonstração de manifestações de intertextualidade caracterizadoras do estilo de crônicas jornalístico-literárias de Arnaldo Jabor. Como o produtor do AC02 já havia discutido, dentre outros aspectos, os tipos de intertextualidade e concepções de estilo, na seção de fundamentação teórica com base em autores como Charaudeau, Bakhtin e Possenti, na seção de análise dos dados, as referências aos fundamentos teóricos são geralmente feitas indiretamente (não marcadas linguisticamente), mediante a retomada de categorias teóricas (citação integral, autotextualidade, intertextualidade, alusão, marca estilística), sem necessariamente o produtor explicitar o(s) autor (es) dos quais foram assumidas, como ilustra o excerto abaixo:

(08)
Porém, devido à citação integral do trecho [20],
neste caso, pode-se caracterizá-lo como um caso
de autotextualidade, ou seja, intertextualidade
com seu próprio texto. Esta forma de expressão
da intertextualidade é comum nos textos de Jabor,
sendo outra marca estilística. Isso ocorre tanto por
meio de citações diretas, quanto por referências ou
alusões. O autor situa-se em um contínuo de tex-
tos, pois pressupõe um reconhecimento, por parte
dos leitores, ao promover um diálogo com outros
textos já publicados, do seu posicionamento e do
seu estilo. (AC02, p. 2231)

O produtor do AC03, por sua vez, sistematiza sua análise focalizando a demonstração de misturas de gêneros constitutivas do scrap a partir do questionamento de trabalhos de outros autores e da proposição 
que ele faz acerca da ocorrência de outros "tipos de mistura que foram além da intergenericidade já conhecida". $O$ esforço de questionar os trabalhos de outros autores implicou a necessidade de o produtor do AC03 fazer constantes referências a aspectos teóricos de trabalhos desses autores, resultando, dessa forma, em uso mais recorrente de citações, como ilustra esse excerto:

[...] Pelo menos todos os exemplares de intertextualidade trazidos na obra de Koch, Bentes e Cavalcante (2007), embora muitos se utilizem de elementos não verbais, trazem o intertexto em sua materialidade linguística. Então será adequado dizer que o intertexto é somente uma "co-incidência de fragmentos de textos" (KOCH, BENTES e CAVALCANTE, 2007, p. 121), quando ele se refere somente a elementos linguísticos? Não pensamos assim. Talvez o conceito de texto e, por consequência, o de intertexto tenham de ser reavaliados permitindo que outros elementos semióticos sejam contemplados ao conceito. [...] Se dissermos, com Cavalcante (2007), que o intertexto é um elemento que permite fazer uma remissão não importa de que natureza - inclusive a gêneros - estaremos reduzindo gênero a texto.

O que queremos dizer é que, para que se mantenha operante a expressão intertextualidade intergenérica é necessário o alargamento do conceito de texto $e$, por conseguinte, o de intertexto, que pode ser entendido como qualquer elemento que possibilite fazer referência a outro texto ou a outro gênero, $e$ não somente à materialidade verbal. Numa relação intergenérica, o intertexto pode ser a estrutura composicional, o conteúdo temático ou até mesmo o estilo. [...] (AC03, p. 4356-4357)

Nesse caso, o tom de questionamento em relação a formulações teóricas de outros autores é determinante quanto à referência explícita que o produtor de $\mathrm{AC0} 3$ faz a tais autores - Bentes e Cavalcante (2007), Koch, Bentes e Cavalcante (2007) e Cavalcante (2007) - na seção de análise dos dados. O produtor do AC08, por sua vez, faz constantes referências explícitas aos autores que fundamentaram o trabalho; porém, diferentemente do produtor do $\mathrm{AC03}$, as formulações teóricas dos autores citados não são tomadas para questionamento e o/ ou problematização, mas para dar sustentação à análise que o produtor do texto realiza, de modo que as citações, feitas tanto sob a forma de discurso indireto como de discurso direto, funcionam como uma espécie de comprovação e/ou ratificação dos achados da pesquisa. Essa estratégia pode ser observada no excerto abaixo, em que Authier-Revuz é citada para ratificar a análise que o produtor faz acerca da estratégia de reprodução de palavras:

Neste fragmento, percebemos que, ao discutir sobre o ensino de literatura oferecido pelo livro didático, dando destaque para as implicações negativas que $o$ seu 'mau uso' confere ao tratamento do texto literário, o estudante menciona, em discurso citado indireto, o que diz Zilberman (1984). Neste caso, o discurso de Zilberman é interpretado pelo estudante no sentido de atribuir a essa autora a afirmação de que o livro didático brasileiro inclui textos produzidos por autores contemporâneos da literatura nacional, mas norteado por práticas que nivelam a polissemia literária [...]. Podemos observar, então, que o estudante se comporta como "tradutor" do discurso de Zilberman (1984), de modo que não sabemos exatamente que palavras a autora usou, de fato, ao discorrer sobre o assunto; mas se imagina que as palavras usadas pelo estudante se constituem como um equivalente semântico dos dizeres daquela. Segundo Authier-Revuz (2004, p.12): "fazendo uso de suas próprias palavras, ele [o enunciador] remete a um outro como fonte do 'sentido' dos propósitos que ele cita". Assim, como bem vemos no fragmento, o estudante não se preocupa em citar fielmente as palavras do discurso fonte, mas em extrair delas um sentido, para, desse modo, apoiar o seu próprio dizer. (AC08, 2077)

Tendo em conta que posturas como questionar, avaliar criticamente e polemizar o dizer do outro e estabelecer distância crítica tendem, exceto em significativa parte do texto do produtor do AC03, a ceder lugar a uma relação fundamentalmente respeitosa frente aos autores, os jovens pesquisadores costumam, na seção de análise, "aplicar" os fundamentos teóricos, no sentido de retomar conceitos/categorias de análise, sem entrar no mérito de questionar sua verdade e validade. Isso, geralmente, acaba se refletindo na maneira e na intensidade como as formas de referência a outras fontes se manifestam na seção de análise dos dados dos textos dos jovens pesquisadores.

É interessante anotar ainda que, nessa seção, as referências explícitas a outros autores não cumprem a 
função de comparar os resultados do próprio trabalho do pesquisador com os resultados de outras pesquisas, o que nos parece confirmar o que assinalara Navarro (2014) sobre os modos de construção do conhecimento na área de humanidades, a saber: que o conhecimento não se constrói cumulativamente. Pode-se conjecturar que, no domínio disciplinar em que se inscreve a proposta dos textos dos jovens pesquisadores, os pesquisadores (mais experientes) não valorizem, na sessão de análise dos dados, o diálogo com outros autores com esse propósito de comparar, seja no sentido de confirmar, seja de contrastar, resultados de pesquisas, que é um procedimento comum em trabalhos de pesquisadores de outras áreas, como afirma Day (2001) e como indica a síntese da organização retórica da seção análise e discussão dos resultados apresentada por Motta-Roth e Hendges (2010).

Tal como a seção de metodologia, a seção de conclusão dos artigos científicos analisados resguarda a especificidade de se constituir um segmento textual geralmente muito curto. É necessário mencionarmos que, nos textos analisados, o volume/extensão textual da seção de conclusão se mostra relativamente bastante variável. Há desde textos com 01 página, como AC04, AC05 e AC06, a textos com 02 parágrafos tão somente, como AC03, AC08 e A09. É necessário destacar o volume textual da seção, porque nos parece que a extensão desse segmento textual tem implicação sobre que informações o produtor privilegia e, consequentemente, sobre o manejo das formas de discurso citado, muito embora encontremos conclusões mais longas, com extensão de 01 página, como é o caso de AC06, em cujo texto o produtor não faz referência explícita alguma a autores. Esse é o típico caso que deva ser considerado mais como evento singular, como caso mais eventual, do que como uma prática marcada por regularidades na escrita do artigo científico dos jovens pesquisadores.

É possível observar claramente que textos, como AC08, cuja conclusão se limita a sumarizar os (principais) resultados da pesquisa e a discutir suas implicações, e AC03, em que a conclusão se centra em sumarizar e avaliar os (principais) resultados da pesquisa, costumam não abrir espaço para manifestações explícitas da presença da palavra do outro no dizer do jovem pesquisador. Por sua vez, textos como AC04 e AC05, em cujas conclusões, além de sumarizarem os (principais) resultados da pesquisa, os produtores retomam o tópico estudado, objetivos, conceitos, posições teóricas e fazem menção a autores nos quais se fundamentam, a referência ao dizer do outro acaba se revelando uma estratégia (quase) inevitável. Nos 03 excertos que seguem, recortados de tais artigos, a exploração de elementos como posições teóricas e a explicitação de autores nos quais os produtores fundamentam o seu trabalho (AC04 e AC05) e a retomada de conceitos/categorias das perspectivas teóricas que orientam o estudo (AC05) evidenciam as finalidades do uso do dizer do outro na seção de conclusão dos artigos científicos dos jovens pesquisadores:

\section{(11)}

Bakhtin parte do princípio de que o texto aparece como ponto de interseção de muitos diálogos, apresentando um cruzamento de vozes oriundas de práticas de linguagem diversificadas, o que constitui a polifonia. Charaudeau aborda a teoria dos sujeitos da linguagem, sujeitos que se produzem em função de uma rede de lugares que eles ocupam nesse ato de linguagem. (AC05, p. 208).

Com base na fundamentação teórica adotada e a partir dos corpus extraído de atividades de Português/Redação realizadas em âmbito escolar, o qual apresenta um material de análise propício à investigação e enfoque linguístico almejado, procurou-se fazer uma correlação entre o estudo de transmutação dos gêneros discursivos em Bakhtin (2003) e a escrita digital presente em scraps do Orkut. A partir daí analisa-se a migração desta escrita para recados/bilhetes que utilizam como suporte o papel (gêneros que supostamente deram origem ao scrap). (AC04, p.4315)

Bakhtin, obviamente, nada disse sobre a comunicação das modernas mídias digitais, mas suas formulações convergem e muito contribuem para a o entendimento delas. Assim, a pesquisa é consonante com a teoria bakhtiniana da transmutação dos gêneros, que é uma tendência, principalmente diante dos avanços digitais e das necessidades comunicativas. Na concepção bakhtiniana, todas as esferas da atividade humana, por mais variadas que sejam, estão sempre relacionadas com a 
utilização da língua. Os gêneros representam a língua viva, a língua em uso. O contato com diversos gêneros discursivos exercita a competência linguística dos falantes. (AC04, p.4315)

O mais frequente na seção de conclusão é, porém, os produtores não fazerem referências explícitas a autores. AC02, AC03, AC06, AC07, AC08 e AC09 comprovam esse fato. Além do mais, quando citam, nessa seção, esses produtores tendem a não diversificar nos tipos de citação, utilizando-se mais geralmente de formas de discurso citado que implicam condensação e reformulação das palavras alheias tais como evocação (AC04, AC09) e discurso indireto (AC04, AC05). Se, por um lado, está o componente do estilo individual do produtor, inclusive de "determinar" o volume textual da seção de conclusão, por outro lado, não podemos desconsiderar que, como as "regras do jogo" sobre o uso de citações na seção de conclusão não são bem claras e/ou bem definidas (por força e influência, muito provavelmente, de discursos que emanam de áreas das ciências naturais, mas não apenas delas, escutamos ainda, não sem frequência, estudantes nos perguntarem se é permitido citar ou como devem citar na conclusão ou na introdução de um trabalho científico) nem em manuais de metodologia científica, tampouco em discursos (e trabalhos científicos) de professores, é possível supor também que o jovem pesquisador pode fazer uso das citações em tal seção muito intuitivamente ou porque observou e assimilou de um trabalho de um pesquisador mais experiente, sem saber exatamente se deveria ou não citar.

Não menos importante é destacar que, por vezes, esses estudantes/jovens pesquisadores são confrontados com exemplos de textos/artigos científicos de pesquisadores experientes nos quais as conclusões ora trazem citações explícitas, ora não trazem, o que somadas às demais questões, pode colocar esses estudantes em situação de dúvida e/ou de conflito quanto à possibilidade de fazer uso ou não do discurso citado, especialmente sob a forma de discurso direto, mas também sobre que informações eles precisam apresentar em tal seção para satisfazerem em alguma medida as exigências do gênero. Isso faz pensar no que dizem Pollet $\mathrm{e}$ Piette (2002) sobre a escrita de estudantes de gradu- ação: eles sabem que devem fazer, mas não sabem nem porque e nem como (o como pode ser entendido, conforme faz pensar a análise empreendida, também no sentido de em quais seções se pode citar e de que formas se deve citar em determinada seção).

Considerando a macroestrutura textual global dos artigos científicos e a distribuição das formas de citar nessa macroestrutura, sintetizamos os seguintes achados e compreensões. Observamos que os jovens pesquisadores privilegiam formas de discurso citado que implicam a reformulação e ou condensação do dizer do outro tanto quanto as formas que implicam a reprodução literal do dizer. É possível afirmar que as formas de referência ao discurso do outro que implicam reprodução literal do dizer se concentram de maneira especial na seção de fundamentação teórica, enquanto nas demais seções se observa um predomínio de formas de referência ao discurso do outro que implicam a reformulação e ou condensação do dizer do outro.

Pode-se observar que, enquanto o uso do discurso direto se concentra mais na seção de fundamentação teórica, o discurso indireto, a modalização em discurso segundo sobre o conteúdo e a evocação são as formas mais privilegiadas em seções como introdução e conclusão. Logo, isso confirma que o uso de determinada forma de discurso citado sofre forte determinação da especificidade da função de cada seção na organização retórica do gênero. Assim é que, por exemplo, na introdução, se faz uso da evocação com a finalidade mais específica, e comumente esperada em tal seção, de explicitar autores ou perspectivas teóricas que fundamentam o trabalho do pesquisador, mas também de demarcar pesquisas prévias dentro do propósito do produtor de proceder à problematização da pesquisa e à delimitação do tema, como mostra o caso do produtor de AC08.

\section{Conclusão}

A análise realizada nos permite confirmar que formas e finalidades de uso do discurso citato no artigo científico do jovem pesquisador sofrem inevitavelmente forte determinação da seção do artigo nas quais são mobilizadas, mas também do modo pessoal como o produtor seleciona e organiza as informações em seu 
texto, revelando aí claramente a maneira como a tensão entre o estilo do gênero e estilo individual do produtor caracteriza o uso do discurso citado na escrita do artigo científico do jovem pesquisador.

Nossa leitura sugere afirmar ainda que o estilo individual do produtor que se revela nesses textos não pode ser pensado, nesse caso, sem observar o estágio de formação em que se encontra o pesquisador, já que, como vimos, alguns dos usos do discurso citado parecem indicar ou desconhecimento de certas convenções da escrita científica e/ou mesmo dificuldades inerentes à condição em que ele se encontra, quando não o uso intuitivo de alguns dos modos de citar, aspecto esse que, evidentemente, também não pode ser apartado do estágio da formação do estudante/pesquisador.

Esses achados nos colocam sob a necessidade de (re)conhecermos a complexidade do citar na constituição do dizer do jovem pesquisador, tentando enxergar, com base no que afirma Petrić (2012), que determinados usos do discurso citado são inerentes ao desenvolvimento do letramento acadêmico e à aquisição de um discurso disciplinar. Assim, dificuldades de gerenciamento de vozes, de citar adequadamente, de maneira relevante e produtiva, que textos de jovens pesquisadores apresentam podem, muitas vezes, ser melhor compreendidos não como um atestado de inabilidade ou simplesmente como problemas de leitura, mas como fazendo parte de um processo de desenvolvimento do letramento acadêmico e de familiarização do jovem pesquisador com as convenções da esfera acadêmica e com o discurso disciplinar.

Entendendo, pois, as dificuldades que a condição de ser jovem pesquisador impõem em relação ao domínio pleno dos gêneros acadêmico-científicos e de familiarização com as convenções e "regras do jogo" (algumas vezes, confusas; outras vezes, paradoxais) da esfera acadêmico-científica, é necessário pensarmos, enquanto possibilidade de colaborar para potencializar a qualidade e a relevância da produção científica de nossos pós-graduandos, propostas de trabalho mais sistemático e de orientação pontual quanto às práticas de citação na escrita de textos acadêmicos-científicos. Sustentamos a necessidade de se considerar, nessas propostas, dentre outros aspectos, as especificidades disciplinares, o modo de funcionamento das citações de acordo com o gênero do discurso e sua organização retórica, os espaços de circulação desses textos e a questão não menos importante de se considerar o estatuto do produtor na escala de produção do saber no campo científico.

\section{Notes}

1. Nosso interesse específico pelas práticas comunicativas das humanidades, e em especial de Letras e Linguística, comunga de um posicionamento político em torno da questão da escrita científica assumido por Boch (2013), que estendemos ao contexto brasileiro, e que se expressa nos seguintes termos: "Militamos, então, em favor da multiplicação dos estudos linguísticos sobre a escrita científica, em particular em francês e em ciências humanas, ainda pouco representados." (p. 565 , tradução e grifos de nossa responsabilidade).

2. Reconhecemos os riscos e a dificuldade que são encontrar um termo para melhor caracterizar a condição na qual se encontra o estudante de mestrado, considerando que poderíamos pensar em termos como neófito, novato, iniciante, principiante, aprendiz, entre outros, recorrentes em textos de pesquisadores da área. Resolvemos, contudo, adotar o termo jovem pesquisador tomando como base um estudo de Boch (2013), ainda que ela o utilize para se referir também a estudantes de doutorado. A autora usa o termo em oposição a pesquisadores experientes, profissionais. É, portanto, a condição de aprendiz (não expert) da escrita científica que a autora usa para caracterizar o termo jovem pesquisador pela qual nos orientamos aqui. Concebemos o mestrado como um lugar de transição na formação do pesquisador considerando que, nesse estágio, o estudante se encontra ainda, como assevera Severino (2009), em uma fase de aprendizagem da pesquisa e de formação como pesquisador. Corrobora também a nossa posição de conceber o mestrado como um lugar de transição na formação do pesquisador o nível de exigência dos textos e trabalhos produzidos durante esse estágio no que concerne, por exemplo, ao tipo de reflexão empreendida, tendo em conta que a escrita da dissertação de mestrado se apresenta ainda para muitos como a "[...] primeira manifestação de trabalho pessoal sistemático de pesquisa [...]” (SEVERINO, 2009, p. 24), contrastando com as exigências requeridas na escrita da tese de doutorado, já que, conforme Kapp (2012, p. 252), com quem concordamos, "fazer uma tese é já conduzir uma pesquisa"; logo o estudante/pesquisador deve demonstrar a competência de especialista em sua disciplina, o que implica, por conseguinte, um grau 
maior de responsabilidade e autoridade sobre o que ele enuncia (SAVIO, 2010).

3. No modelo CARS de introdução de artigos desenvolvido por Swales (1990), no qual Motta-Roth e Hendges (2010) se fundamentam, o autor utiliza o termo sub-movimentos. Respeitamos, aqui, porém, o termo que elas utilizam.

4. Para assegurar a preservação da identidade dos autores, os artigos científicos foram codificados observando a seguinte identificação: AC01, AC02, AC03..., em que AC corresponde a Artigo Científico e os numerais $01,02,03 \ldots$ correspondem à ordem numérica, estabelecida aleatoriamente, dos textos em nosso corpus. Acompanhando a identificação, encontra-se a indicação da página do artigo da qual o excerto foi recortado. Redução do tamanho da fonte e destaques de negrito (com exceção do excerto 7), itálico e sublinhado nos excertos são de nossa responsabilidade, visando a melhor realçar aspectos que analisamos.

\section{Referências}

ASSOCIAÇÃO BRASILEIRA DENORMAS TÉCNICAS - ABNT. NBR 6022: informação e documentação: artigo em publicação periódica científica impressa apresentação. Rio de Janeiro: ABNT, 2002.

AUTHIER-REVUZ, J. A representação do discurso outro: um campo multiplamente heterogêneo. Tradução de Daniel Costa da Silva e revisão de Marlene Teixeira. Calidoscópio, vol. 6, n. 2, p. 107-119, maio./ago. 2008.

. Entre a transparência e a opacidade: um estudo enunciativo do sentido. Porto Alegre: EDIPUCRS, 2004 .

. Palavras incertas: as não-coincidências do dizer. Tradução de Claudia R. Castellanos Pfeiffer, et al. Revisão técnica da tradução Eni Pulccinelli Orlandi. Campinas, SP: Editora da UNICAMP, 1998.

BAKHTIN, M. Os gêneros do discurso. In: Estética da criação verbal. Tradução do russo de Paulo Bezerra. 4. ed. São Paulo: Martins Fontes, 2003, p. 261-306.

BESSA, José Cezinaldo Rocha. Dialogismo e construção da voz autoral na escrita do texto científico de jovens pesquisadores. 2016. 360 f. Tese (Doutorado em Linguística e Língua Portuguesa), Pós-Graduação em Linguística e Língua Portuguesa, Universidade Estadual Paulista "Júlio de Mesquita Filho", Araraquara, 2016.

BOCH, F; GROSSMANN, F. Referir-se ao discurso do outro: alguns elementos de comparação entre especialistas e principiantes. Scripta, v. 6, n.11, p. 97108, 2002.

$\mathrm{BOCH}, \mathrm{F}$. Former les doctorants à l'écriture de la thèse en exploitant les études descriptives de l'écrit scientifique.
Linguagem em (Dis)curso, Tubarão, SC, v. 13, n. 3, p. 543-568, set./dez. 2013.

DAY, R. A. Como escrever e publicar um artigo científico. Tradução de Marina André de Alvarez. 5. ed. São Paulo: Livraria e Editora Santos, 2001.

KANOKSILAPATHAM, B. Rhetorical structure of biochemistry research articles. English for Specific Purposes, v. 24, n.3, p. 269-292, 2005.

KAPP, S. Premiers textes : socialisation à l'écriture et formation des doctorants. SCRIPTA, Belo Horizonte, v. 16, n. 30, p. 251-266, $1^{\circ}$ sem. 2012.

LONG, D. Définir une problématique de recherche, 2004. Documento eletrônico. Disponível em: <http:// web.umoncton.ca/umcm-longd02/TheorixDownload/ probleme.pdf>. Acesso em 24 mar. 2015.

MAINGUENEAU, D. Análise de textos de comunicação. Tradução de Cecília P. de Souza-e-Silva e Décio Rocha. 6. ed. São Paulo: Cortez, 2011.

Gênese dos discursos. Tradução de Sírio Possenti. São Paulo: Parábola Editorial, 2008.

Novas tendências em Análise do Discurso. Tradução de Freda Indursky. 3. ed. Campinas, SP: Pontes: Editora da Unicamp, 1997.

Elementos de lingüística para o texto literário. Tradução de Maria Augusta Bastos de Mattos. São Paulo: Martins Fontes, 1996.

MOTTA-ROTH, D.; HENDGES, G. R. Produção textual na universidade. São Paulo: Parábola Editorial, 2010.

NAVARRO, F. Géneros discursivos e ingresso a las culturas disciplinares: aportes para uma didáctica de la lectura y la escritura en educación superior. In: (Coord.). Manual de escritura para carreras de humanidades. Ciudad Autónoma de Buenos Aires: Editorial de la Facultad de Filosofía y Letras Universidad de Buenos Aires, 2014, p. 29-52.

PETRIĆ, B. PETRIĆ, B. Legitimate textual borrowing: direct quotation in L2 student writing. Journal of Second Language Writing, 21, p. 102-117, 2012.

POLLET, M. C.; PIETTE, V. Citation, reformulation du discours d'autrui. Une clé pour enseigner l'écriture de recherche ? Spirale, n. 29, p. 165-179, 2002.

RODRIGUES, R. H. Análise de gêneros do discurso na teoria bakhtiniana: algumas questões teóricas e metodológicas. Linguagem em (Dis)curso, Tubarão, v. 4, n. 2, p. 415-440, jan./jun. 2004.

SAVIO, A. K. Las huellas del autor en el discurso académico: un estudio sobre tesis de psicoanalistas argentinos. Lenguaje, 38 (2), 563-590, 2010. 
SEVERINO, A. J. Pós-graduação e pesquisa: o processo de produção e de sistematização do conhecimento. Rev. Diálogo Educ., Curitiba, v. 9, n. 26, p. 13-27, jan./abr. 2009.

SWALES, J. Genre analysis: English in academic and research settings. Cambridge: CUP, 1990.

VOLPATO, G. Dicas para redação científica. 3. ed. São Paulo: Cultura Acadêmica, 2010.

Recebido em: 06/02/2016 Aceito em: 16/03/2016 